\title{
The Fundamental Importance of the Normative Analysis of Health
}

\section{A. M. Viens ${ }^{1}$}

Published online: 19 February 2019

(c) Springer Science+Business Media, LLC, part of Springer Nature 2019

Normative analysis involves thinking in a systematic way about the evaluative (e.g., good, bad, better than) and deontic (e.g., right, wrong, just, unjust, required, prohibited) dimensions of actions, policies and institutions. This includes identifying and assessing normative reasons, evidence and argumentation about, for instance, the objectives and aims of governance, prioritization of ends, allocation of resources, and the scope and limits of resulting rights, obligations, and responsibilities. This means advancing prescriptive or evaluative value-based statements in the construction of recommendations about how we should understand an issue, what kind of action should be undertaken, or which type of policy ought to be advanced. In the context of health, normative analysis seeks to employ normative theories, frameworks, methods, concepts, principles, and values in order to better comprehend the moral, political, and legal nature of, and improve the practice of, health care, public health, policy, and research.

The incorporation and use of normative analysis of health is fundamentally important in order to help us understand what health is, why health should be protected, why we should care about inequalities in the distribution of health determinants and outcomes, and what means it would be permissible to employ in order to achieve the conditions under which people can be healthy and enjoy health equity. We need normative analysis to interrogate the soundness of normative premises, to help us closely examine the value judgments underpinning policy and practice, and ensure our actions and institutions are justified and legitimate. Normative analysis also helps to elucidate how health policies or practices may be fragmented, inconsistent, implausible, contradictory, or incomplete. This emphasises not only the importance of distinguishing between the technical and normative aspects of health and health care, but seeking to figure out the best ways to integrate and combine the technical and normative components of health policy, practice, and research. Ultimately, the normative analysis of health seeks to advance critical engagement and

\section{A. M. Viens}

hca.springer@gmail.com

1 Centre for Health, Ethics and Law (HEAL), University of Southampton, Southampton, UK 
inquiry about the proper place and shape of health in our personal lives, social relations, and political institutions.

\section{Advancing Dialogue Between Health, Philosophy and Policy Through Normative Analysis}

Health Care Analysis is a journal that promotes dialogue and debate about conceptual and normative issues related to health and health care, including health systems, health care provision, health law, public policy and health, professional health practice, health services organisation and decision-making, and health-related education at all levels of clinical medicine, public health, and global health. It is committed to the view that all aspects of health-from the social determinants of health, to health care delivery, to health systems - are interrelated, and publishes papers that explore links between these areas.

As a journal for everyone interested in philosophical issues surrounding health and health care, Health Care Analysis seeks to support the conversation between philosophy and policy, and illustrate the importance of conceptual and normative analysis to health policy, practice, and research. It publishes contributions from philosophers, lawyers, social scientists, health care educators, health care professionals and administrators, and other health-related academics and policy analysts. The Journal seeks to publish high-quality, innovative, and novel research which reflects a diversity of approaches and areas of investigation interested in exploring conceptual and normative questions related to all aspects of health broadly understood. As Cribb [3] has noted: "Its purpose is philosophical-but it is not written by, or for, professional philosophers alone. This has always been the underlying organizing principle of the journal, and it is this which gives it its distinctiveness".

In preparation for writing my first editorial for Health Care Analysis, I had the pleasure of reviewing the editorials of past Editors-in-Chief when taking over or leaving their role [1-5]. It was heartening to read how the mission and approach of the Journal has consistently been reflected and strengthened over the years around the interrelation between health, philosophy, and policy - and their advocacy of the importance of analysing these relations. I am humbled to follow these distinguished editors emeriti and to continue their legacy of providing a preeminent venue for connecting normative theory, health policy, and health practice.

\section{Heath Care Analysis: The Next Phase}

I am very proud and excited to be taking over as Editor-in-Chief of Health Care Analysis. It is daunting yet invigorating to be given the opportunity to carry on the mantle of what has been accomplished by the Journal's past Editors-in-Chief. Under their direction, John Coggon (2014-2018), Andrew Edgar (2006-2014), Alan Cribb (1999-2006) and David Seedhouse (1993-1999) have adeptly and persistently created a distinctive academic venue for dialogue between health, philosophy, and policy that has steadily attracted influential articles, noteworthy special issues, engaging 
debates, and an increasing impact factor. I am particularly grateful to John Coggon who brought me on as an Associate Editor, and characteristically provided supportive encouragement and collaborative partnership from which I learned a great deal.

In taking over the editorial helm, I have used the opportunity to refresh and update a number of key aspects of the Journal. I have ensured that our editorial and advisory boards, as well as associate editors, are even more reflective the Journal's mission and approach-they are more international, more gender-balanced, more disciplinarily rich. It is hoped that these changes will further attract first-rate submissions from both high-income and low- and middle-income countries.

We have also adopted a new cover. I remember as an eager undergraduate student, in between classes, heading over to the section of the university library where new journal issues were placed. With all of their colourful covers laid out, I would expectantly turn them over to inspect their tables of contents and decide which articles to read there and then or to photocopy for later reading. Today, however, the way in which we access journal articles is much different. While we rarely spend time looking at journal covers, we have updated the cover to reflect its vibrant and modern nature. This will be seen on the Journal website, electronic table of content alerts and social media—such as the Journal's new Twitter (@ HCAnalysis).

With the support Janet Kim (senior editor for Springer), the wonderful editorial and technical team who support the production of the Journal, the Journal's editorial and advisory boards, and the Journal's authors and peer-reviewers, I am looking forward to the next phase of Health Care Analysis and seeing its continued positive contributions to academia, policy, and society.

\section{References}

1. Coggon, J. (2014). Health care analysis: Advancing discourses between philosophy, health, and policy. Health Care Analysis, 22, 103-104.

2. Coggon, J. (2018). New horizons for health care analysis. Health Care Analysis, 26, 285-286.

3. Cribb, A. (1999). Editorial. Health Care Analysis, 7, 1-3.

4. Edgar, A. (2014). Editorial. Health Care Analysis, 22, 1-2.

5. Seedhouse, D. (1993). Putting the horse first: The practical value of philosophical analysis. Health Care Analysis, 1, 1-3.

Publisher's Note Springer Nature remains neutral with regard to jurisdictional claims in published maps and institutional affiliations. 